\title{
Quantitative Systems Pharmacology: A Framework for Context
}

\author{
Ioannis P. Androulakis ${ }^{1}$
}

Published online: 8 April 2016

(C) Springer International Publishing AG 2016

\begin{abstract}
Quantitative Systems Pharmacology (QSP) is receiving increased attention. As the momentum builds and the expectations grow it is important to (re)assess and formalize the basic concepts and approaches. In this short review, I argue that QSP, in addition to enabling the rational integration of data and development of complex models, maybe more importantly, provides the foundations for developing an integrated framework for the assessment of drugs and their impact on disease within a broader context expanding the envelope to account in great detail for physiology, environment, and prior history. I articulate some of the critical enablers, major obstacles, and exciting opportunities manifesting themselves along the way. Charting such overarching themes will enable practitioners to identify major and defining factors as the field progressively moves towards personalized and precision healthcare delivery.
\end{abstract}

Keywords Quantitative systems pharmacology ·

Inflammation $\cdot$ Chronic disease $\cdot$ PKPD

\section{Introduction}

In recent years there have been numerous reports discussing opportunities, progress, and successes of Quantitative Systems Pharmacology $[8,67,101]$, referred to as QSP

This article is part of the Topical Collection on Pharmacometrics

Ioannis P. Androulakis

yannis@rci.rutgers.edu

1 Biomedical Engineering Department, Chemical and Biochemical Engineering Department, Rutgers University, Piscataway, NJ 08854, USA onwards. Multiple definitions have been provided in the literature and, as such, I will refrain from attempting yet another description of the term. It is by now most likely evident that the term QSP encompasses approaches related to the integrated analysis of complex (and simple) models in an attempt to rationalize drug action. The implications are expected to be many fold including, but not limited to, predicting an individual's response to treatment, assessing efficacy and safety, and enabling the rational design, and rationalization of results, of clinical trials. QSP modeling approaches most often do not address discovery needs and most likely are developed during the later pre-clinical stages with the expectation to provide critical insight during the clinical stages of drug development $[31,54,55]$.

While mathematical and computer modeling is at the core of QSP, it most likely is not appropriate to focus exclusively on those aspects alone when talking about QSP. After all, in some shape or form, modeling in pharmacology has been around for decades, likely as far back as the 1960s with Gerhard Levy's pioneering work on the kinetics of pharmacologic effects $[68,69]$. Models have since increased substantially in complexity not only because of our increased fundamental understanding of biology, pharmacology, and physiology and our improved ability to probe physiological systems and accumulate high-quality and high-dimension data, but also because of computational sciences and systems approaches that were formally adopted by traditional pharmacokineticists, thus rendering the process of developing and using complex models tractable, and the interpretation of the results more meaningful.

However, it would likely be rather shortsighted to limit the potential contributions of QSP strictly to the development of computational models, however more complex. In fact, the purpose of this review is to argue that QSP's main contribution is not whether it could deliver "more of the same", i.e., more 
complex models, but rather the fact that QSP can act as a framework within which we can begin to phrase a suite of questions of increasing complexity. QSP as a framework will enable us to place drugs and their pharmacologic actions within their proper broader context, which we realize extends beyond the site of action. This, I subsequently argue, will become a major and defining factor as we progressively move towards personalized and precision healthcare delivery.

\section{Evolving Role of Modeling in Pharmacology}

Without delving into too much technical detail, I will simply state that the term modeling, as used in the context of this paper, denotes the quantitative description of the dynamics of a system of interest using mathematical and computational approaches. I make use of the terms "mathematical" and "computational" broadly at this point so as not to limit the discussion in any way in that respect. In that sense, mathematical models have been introduced in pharmacology over half a century ago, likely originating from the pioneering work of Gerhard Levy, recently published in a summary [33]. From that point on, pharmacokinetic and pharmacodynamic models have been used to assess how much drug is available following a specific route of administration, whether it hits the target, whether it performs the actions it was designed to perform, and, finally and more importantly, whether it generates the expected outcome [120]. Along with these questions, it also becomes important to assess the extent to which the drug would also induce secondary, direct, indirect, synergistic, or antagonistic effects - desirable or not. The value of modeling was realized early on as, likely, a critical enabler to assess critical questions such as identifying dose limits, dose effects, and, of course, extrapolation (animals to humans, adults to pediatrics, etc.) $[22,75]$.

The models have, therefore, historically evolved to describe drug levels in circulation, connect drug levels directly to outcome using phenomenological expressions, connect drug levels to cellular functions and connect drug levels to outcome. Developments in pharmacology and the development of approaches integrating physiology with pharmacology with models evolving from simple pharmacokinetics to compartment to comprehensive model accounting for physiologic considerations [1] led to development of more complete models better accounting for drug liberation, absorption, disposition, metabolism, and excretion (LADME) to describe drug release from formulation, pharmacokinetics, as well as signaling and regulation at the level of cell to capture the pharmacodynamics $[16,89,99]$. The incorporation of parameters reflecting physiology was a critical step in addressing the fundamental issue of extrapolating animal data to humans [74, 91]. The physiological basis of PBPK models easily allows us to extend these to include PD considerations beyond simple receptor binding [93].

The advances in systems in biology and pharmacology, both conceptual in terms of network analysis as well as experimental in terms of readily generating -omics information, enabled researchers to increase the complexity of the analysis by simultaneously accounting for multiple complimentary, synergistic, and antagonistic pathways, mostly intracellularly $[12,15,118]$. As such, we recognized the importance of considering drug targets as part of a network of interacting elements (genes, proteins, or metabolites) and recognized that information is not propagated in a strictly linear manner, but in rather convoluted ways as these emerge through complex networks [112].

Systems pharmacology approaches enabled us to increase the complexity of our models by expanding the pathways and modes of action, accounting for multiple simultaneous interactions [49]. Continued advances in high throughput-omics technologies facilitated the collection of information at the genomic, transcriptomic, metabolomic, and proteomic levels, as well as at regulatory and epigenomic levels. This wealth of information enabled us to further increase the complexity of our models by expanding the chain of events activated, or suppressed, as a result of a drug's action [51]. Highthroughput analysis enabled us to decipher differences related to, for example, dosing [81] or tissue dependencies [83].

In the sections that follow, I wish to address broader issues related to challenges and opportunities of QSP, and its potential to define the future.

\section{QSP: The Framework}

QSP, as a framework, has emerged and morphed into an integrated and integrative approach, which relies heavily on exploring systems analysis and quantitative modeling approaches and methodologies for rationalizing the wealth of information generated by in vivo and in vitro systems and developing quantitative predictions. QSP capitalized, explored, and in some cases introduced novel computational methods formalizing the analysis and modeling approaches. The versatility of the available methods was critical in order to appreciate that different computational approaches are better suited for different types of pharmacological systems and questions. The phenomenal advances in computational and data sciences provide flexible and user-friendly computational environments making the use of sophisticated tools easily, and seamlessly adopted by a wide range of practitioners, addressing a multitude of problems across a broad spectrum of applications from disease models to drug function, to the implications of drug formulation [3, 20, 30, 39, 57, 59, 73, 76, 90, 92, 95, 97, 98, 113, 119]. 
From a computational point of view parameter estimation and model selection has, likely, been at the top of the list of critical challenges. However, the community has embraced systems approaches and has evolved them to a high level of standards $[7,9,72]$.

It could be argued that a most critical roadblock towards the systematic development of QSP models is that apparent lack of standardization of models, and model components [37]. This is a fundamental issue which, although receiving increased attention, underlies essential difficulties. In more mature science and engineering fields, so-called "modular process simulators" enable the automated development of complex structures in the form of networked elements, each characterized by its own dynamics. However, each component and element of the network is well annotated and described by appropriate constitutive equations. Each element of the network can be represented as an appropriate object in modular form [18], whereas the equation-oriented formalism enables the exact representation of each module by a set of detailed mathematical equations [84]. Assembling of individual models can easily be automated in a "drag-and-drop" manner and complex models can therefore be generated and analyzed in great detail. However, the so-called "flow sheet optimization" in the chemical process industries is an activity which has been in development for decades [34], and, furthermore, since it focuses on engineered constructs, the details of the dynamics of each constitutive module and element are well understood. As a result, modules are interchangeable and complex networks can be built by appropriately linking said modules in ways dictated by specific applications, regardless of the complexity or the module or the network.

However, QSP models/modules do not have a quality yet comparable to their engineering counterparts. In QSP, the constitutive modules are often the purpose of the analysis, reflective of the fundamental differences between Complex Engineered and Complex Biological Systems [4]. Unlike engineered systems, in complex biological (and pharmacological) systems, the constitutive elements of the network modules need to be identified through perturbations, which will uncover different aspect of their dynamics, which need to be quantified depending on the perturbation. At a higher level, indirect response modeling replicates this formalism, in the sense that the certain structures (such as indirect activation or inhibition of production/synthesis of a mediator, receptormediated processes, and transit compartments, to name a few) can be made interchangeable with appropriately adjusted parameters $[42,62,121]$. However, the question is whether the mathematical description of a signaling pathway targeted by a drug, for example, can be easily rendered ubiquitous and interchangeable as the analysis moves from one drug molecule, or disease, to another. Consider for example a critical, and rather pervasive, signaling pathway such as NfkB. Even though it represents a relatively common player in model development, numerous alternative representations have emerged [19, 117]. These reflect not only differences in the level of complexity that is required, or desired, but also differences in the way the elements of the signaling pathway present themselves, depending on the perturbation employed to reveal the wiring of the pathway $[5,64,82,83]$.

Interestingly, the practitioners have expressed the need for standards as well as the concerns outlined above. An insightful discussion based on practitioners' input was presented in [56] where the challenges were nicely articulated: "[...] $80 \%$ of the respondents consider the creation of [modeling] standards necessary or desirable: standards are expected to improve model reuse, expandability and integration, and allow for more productive collaboration [...] standards improve communication between software tools, free exchange of information and comparison between different studies [...] reimplementation of models becomes easier or dispensable, which reduces the duplication of work and the possibility of implementation errors. Theoreticians and software developers need benchmark data as experimentally verified gold standards to apply and to improve their methods [...] respondents also expressed the concern that standards should be flexible, not become too restrictive and not prevent alternatives or new developments. Those respondents who were against standards argued that biology is too complex to be standardized and obeying standards may cause practical difficulties." However, a number of efforts are currently under way aiming at developing model standardization frameworks [27, 31, 32, 44, 45, 56, 58, 96].

\section{QSP: The Context}

Modeling and computation in the context of upgrading the information content of biological information defined, in the late 1970 s, what eventually came to be known as "bioinformatics," namely the collective efforts aiming at studying the "informatics processes of biotic systems" [43]. The power of the collective methods that have since emerged, and now encompass not only bioinformatics but also systems biology approaches, is that it did not simply enable the faster, and more accurate, interpretation of complex data, i.e., defining the framework, but really enabled us to approach biological questions (or drug actions) from a different, more integrative, perspective, i.e., defining the context [53]. As such, I wish to argue that QSP offers such an opportunity and needs to be evaluated and developed along the same lines, in other words the framework that enables us to place drug action in its broader context. In fact, this is not a methodology issue (see "framework" in preceding section), but it is rather driven by the critical health challenges of the future where the systems (host) view will be required to play a major role. 
Despite the promise and potential of systems biology, "friendly," yet constructive, criticism has indicated that for it to progress to the next level, physiology (i.e., the broader network of defense mechanisms) and environment (socio-economic, lifestyle), in other words the system, need to become part of the analysis [48]. The idea of extending the operating envelope beyond the cell, which by and large has been the focus of most systems biology/pharmacology models focusing on complex signaling pathways and/or modes of action, has gained momentum.

For example, it has been increasingly recognized that a large portion of the health challenges of the 21 st century will be non-communicable conditions with one common, underlying characteristic: persistent, low-grade, systemic inflammation, also known as meta-inflammation [11, 28, 29, 71, 111]. However, inflammation and inflammation-related diseases have been difficult to control and regulate due to the complexity and intertwined character of the response [65]. Inflammation characterizes a reaction critical for survival which evolved to balance redundancy, compensation, and necessity [111]. The balancing of seemingly conflicting objectives is really at the core of what characterizes biological complexity [23]. Because the mechanisms orchestrating the inflammatory response are redundant, targeting one pathway may, and most likely will, not be enough; inhibiting one mechanism may, and most likely will, induce activation of alternatives to compensate; and finally inflammation is necessary for defense and survival, therefore the risk/benefit balance may, and most likely will, not be easily achieved. Obesityassociated inflammation, for example, appears to help to maintain insulin sensitivity, therefore it has also been postulated that anti-inflammatory therapies have failed in the treatment of insulin resistance [35], since inflammation promotes energy expenditure in a feedback manner to counteract an energy surplus to regulate energy balance [123], whereas in peripheral tissues induces it fat mobilization and oxidation to promote energy expenditure. In fact this broader (dys)regulation of energy in the context of chronic inflammatory diseases (such as rheumatoid arthritis) has been beautifully articulated by Straub in a series of papers exploring the systemic implications of chronic inflammation [102, 105-108].

Considering the major challenges of the future, it has already been recognized that diseases such as Alzheimer's and cancer have strong systemic components acting as either a pre-disposing factor or contributing to the development of the disease $[60,61,80,88]$. The systemic nature of cancer is not a recent realization [79]; however, we may now have the opportunity to materialize such ideas for the benefit of drug discovery, disease treatment, and improvement of health, by understanding the systemic aspect of the response mechanisms, their interactions with low-level targets and their reciprocal engagement and activation.
Although the aforementioned analyses point largely to disease etiology, a number of recent studies have also identified the potential of "non-obvious (non-targeted) interventions." The "systemic" view is not simply an abstraction to enable the discussion, but it is rather a major factor in disease etiology and treatment justifying the role and potential of said interventions. Here is a short list of characteristic examples where nonspecific "stressors" and "interventions" lead to disease and enable treatment:

- Social interactions when absent can induce chronic inflammation phenotype, leading to related diseases and allcause mortality [21]; while when present, induce enhanced host response (wound healing), and in fact mimic a drug's effect [115]. What is particularly intriguing, besides the fact that environmental enrichment, or lack of it, can impact specific cellular pathways, is that "mood" modification, either pharmacologically or behaviorally (through nest making), has the ability to induce fundamental changes at the cellular level of peripheral tissues given the intimate relations between brain and the immune system [86] - a concept further explored by allostatic approaches [52].

- Circadian rhythms (central and peripheral) coordinate and integrate a number of functional responses and metabolic cues [6]. The links between reprogramming of peripheral circadian clocks and physiological responses [94] were beautifully exemplified in a series of experiments which aimed at circadian reprogramming via timerestricted feeding (controlling access to food without calorie restriction). It has been shown that timing of access to food, effectively setting metabolic rhythms, impacts tumor growth [70], reverses the liver-specific abnormalities in a model of Huntington's disease [77], and alters high-fat diet metabolism impacting obesity factors [41]. On the other end, shift-work, often associated with disrupted feeding patterns, is a known disease pre-disposition factor [10, 124]. Similarly well established are the links between sleep disruption and immunity [14], whereas the daily [100] and seasonal patterns of inflammation and chronic inflammatory diseases $[26,46,63]$ are well established. Well characterized as well are the links between circadian disruption, inflammation, and mood disorders [2, 36, 87]. In [110], the metabolic engagement of circadian rhythms in support of their health-promoting role was further argued.

- Voluntary regulation of the autonomic nervous system (ANS), often achieved by means of modulating breathing patterns (biofeedback), has a clear impact on the inflammatory response [66]. The link between "relaxation" activities, such as yoga, and impact on ANS-related disease (such as epilepsy, depression, and post-traumatic stress disorder) is becoming more clear [109], while ANSengagement (yoga training) improved response to pharmaceutical treatment in a pulmonary tuberculosis study 
[114]. Therefore, a seemingly non-specific systemic modulation has clearly identifiable impact on cellular, diseaserelated pathways affecting outcome.

- Expectation of a positive outcome was found to induce dopamine release likely impacting manifestation of a placebo effect [24]. Interestingly, genomic studies confirmed genetic pre-disposition of likely activation of an up-/ down-stream dopamine pathway which may help predict predisposition to positive response to placebo [38]. On the other end, expectation of negative outcome was found to be a strong inducer of low-grade, chronic inflammation resulting in heart health decline [116].

The aforementioned list, certainly partial and incomplete, points to a significant realization: response to treatment and development of disease is the result of the orchestrated coordination, and convolution, of a vertically and horizontally integrated network of pathways and function working in tandem. This realization becomes particularly important as we begin to delve deeper into the etiology of chronic disease which is not necessarily the result of a single genetic modification or initiating factor. Thus, this is clearly a major opportunity for QSP to adjust the context of the broader analysis. The implications could be significant not only because the integrated - systemic - approaches will shed light on the pathology, as the result of multiple low-level failures, but will also point to alternative pharmacological interventions supporting peripheral (causative) mechanisms leading to the symptoms and not only treating the symptoms.

\section{QSP: Towards a Framework for Context}

At the core of personalized medicine lies our ability to control the factors influencing disease processes and therapy. Simply put "steering [the right] patients to the right drug at the right dose at the right time" [40]. Key contributors in assessing and predicting drug effects are the drug's properties; the physiological characteristics guiding the processes of liberation, absorption, distribution, metabolism, and excretion (LADME) [59], and the way the drug interacts, affects, and is affected by systemic defense mechanisms maintaining overall health aside from disease state. Among the most critical factors are the patient's sex (male vs. female) and age. Major breakthroughs will result not only from our ability to forecast such physiological implications during the early stages of the development of a drug [50], but also how these would interact beyond the local site of action. The consequences are twofold: to streamline the drug development process by increasing the likelihood of success and reducing time to market through optimal design of formulations, and to enable the development of patientspecific formulations increasing the likelihood of treatment success targeting specific patient sub-populations [25].
Earlier QSP efforts enabled us to extend and expand the concept of context in two ways: extending the "simpler" receptor-ligand effect model toward detailed signaling networks - with the help of pharmacogenomics [47, 122]; whereas PBPK enabled us to better understand the mechanisms and processes that enable the drug to reach its target PBPK [13, 91]. Both conceptual approaches have proven extremely successful and systems models are gaining ever-increasing acceptance, slowly getting to the point where model predictions are emerging in the regulatory arena [85].

The multifactorial and complex nature of the disease challenges of the future will require innovative therapeutic paradigms integrating pathology with therapeutic intervention. QSP can form the foundation of such an approach [67]. I previously argued [4], and wish to re-emphasize in this report, that the integrated approach, allowing us to move beyond the local site of action of a drug, would likely define the way forward for QSP. The concept of allostasis [78, 103, 104] enabled us to realize that pharmacologic restoration of lowlevel parameter targets, such a cytokine levels, to rather illdefined "appropriate" levels can potentially have dire implications, since clamping such physiological parameters makes them insensitive to their systemic role. Furthermore, suppressed signals may induce compensatory actions and contribute to deficient responses, while the network nature of the defense mechanisms will induce lateral changes due to blocking specific low-level mechanisms. Underlying these effects is the fact that pharmacological treatment of low-level targets may preclude, prevent, or hamper the engagement of broader mechanisms (at the systemic level), leading to associated co-morbidities, or to act as predisposition factors [17]. As discussed earlier, unexpected results, such as placebo effects, can likely be explained by recognizing the beneficial implications of activating peripheral (higher-level and nonspecific) indirect defense mechanisms [104].

Moving forward, QSP can not only provide the framework for model development, but also, more importantly, help us define the context within which a drug is expected to function. Given the health challenges of the future, I expect that a more integrated understanding of disease etiology and drug function would be required to approach the health challenges of the future. I propose, therefore, that QSP can help define the context as the intellectual tools needed to advance the field.

Acknowledgments The author gratefully acknowledges financial support from NIH Grant GM082974.

\section{Compliance with Ethical Standards}

Conflict of Interest Ioannis P. Androulakis declares no conflict of interest.

Human and Animal Rights and Informed Consent This article does not contain any studies with human or animal subjects performed by any of the authors. 


\section{References}

1. Aarons L. Physiologically based pharmacokinetic modelling: a sound mechanistic basis is needed. Br J Clin Pharmacol. 2005;60(6):581-3. doi:10.1111/j.1365-2125.2005.02560.x.

2. Alesci S, Martinez PE, Kelkar S, Ilias I, Ronsaville DS, Listwak $\mathrm{SJ}$, et al. Major depression is associated with significant diurnal elevations in plasma interleukin-6 levels, a shift of its circadian rhythm, and loss of physiological complexity in its secretion: clinical implications. J Clin Endocrinol Metab. 2005;90(5):2522-30. doi:10.1210/jc.2004-1667.

3. Allan G, Davis J, Dickins M, Gardner I, Jenkins T, Jones H, et al. Pre-clinical pharmacokinetics of UK-453,061, a novel nonnucleoside reverse transcriptase inhibitor (NNRTI), and use of in silico physiologically based prediction tools to predict the oral pharmacokinetics of UK-453,061 in man. Xenobiotica. 2008;38(6):620-40. doi:10.1080/00498250802069088.

4. Androulakis IP. Systems engineering meets quantitative systems pharmacology: from low-level targets to engaging the host defenses. Wiley Interdiscip Rev Syst Biol Med. 2015;7(3):101-12. doi:10.1002/wsbm.1294.

5. Androulakis IP, Kamisoglu K, Mattick JS. Topology and dynamics of signaling networks: in search of transcriptional control of the inflammatory response. Annu Rev Biomed Eng. 2013;15:1-28. doi:10.1146/annurev-bioeng-071812-152425.

6. Asher G, Schibler U. Crosstalk between components of circadian and metabolic cycles in mammals. Cell Metab. 2011;13(2):12537. doi:10.1016/j.cmet.2011.01.006.

7. Ashyraliyev M, Fomekong-Nanfack Y, Kaandorp JA, Blom JG. Systems biology: parameter estimation for biochemical models. FEBS J. 2009;276(4):886-902. doi:10.1111/j.1742-4658.2008. 06844.x.

8. Bai JP. Quantitative systems pharmacology for shifting the drug discovery and development paradigm. Biopharm Drug Dispos. 2013;34(9):475-6. doi:10.1002/bdd.1870.

9. Baker SM, Poskar CH, Schreiber F, Junker BH. A unified framework for estimating parameters of kinetic biological models. BMC Bioinf. 2015;16:104. doi:10.1186/s12859-015-0500-9.

10. Barclay JL, Husse J, Bode B, Naujokat N, Meyer-Kovac J, Schmid SM, et al. Circadian desynchrony promotes metabolic disruption in a mouse model of shiftwork. PLoS One. 2012;7(5), e37150. doi:10.1371/journal.pone.0037150.

11. Bauer UE, Briss PA, Goodman RA, Bowman BA. Prevention of chronic disease in the 21 st century: elimination of the leading preventable causes of premature death and disability in the USA. Lancet. 2014;384(9937):45-52. doi:10.1016/S0140-6736(14) 60648-6.

12. Berger SI, Iyengar R. Network analyses in systems pharmacology. Bioinformatics. 2009;25(19):2466-72. doi:10.1093/ bioinformatics/btp465.

13. Berlin M, Ruff A, Kesisoglou F, Xu W, Wang MH, Dressman JB. Advances and challenges in PBPK modeling-analysis of factors contributing to the oral absorption of atazanavir, a poorly soluble weak base. Eur J Pharm Biopharm. 2015;93:267-80. doi:10.1016/ j.ejpb.2015.03.031

14. Besedovsky L, Lange T, Born J. Sleep and immune function. Pflugers Arch. 2012;463(1):121-37. doi:10.1007/s00424-0111044-0.

15. Boran AD, Iyengar R. Systems pharmacology. Mt Sinai J Med. 2010;77(4):333-44. doi:10.1002/msj.20191.

16. Bouzom F, Ball K, Perdaems N, Walther B. Physiologically based pharmacokinetic (PBPK) modelling tools: how to fit with our needs? Biopharm Drug Dispos. 2012;33(2):55-71. doi:10.1002/ bdd. 1767 .
17. Brame AL, Singer M. Stressing the obvious? An allostatic look at critical illness. Crit Care Med. 2010;38(10 Suppl):S600-7. doi:10. 1097/CCM.0b013e3181f23e92.

18. Chen J, Adomaitis RA. An object-oriented framework for modular chemical process simulation with semiconductor processing applications. Comput Chem Eng. 2006;30(9):1354-80. doi:10. 1016/j.compchemeng.2006.03.002.

19. Cheong R, Hoffmann A, Levchenko A. Understanding NFkappaB signaling via mathematical modeling. Mol Syst Biol. 2008;4:192. doi:10.1038/msb.2008.30.

20. Chetty M, Rose RH, Abduljalil K, Patel N, Lu G, Cain T, et al. Applications of linking PBPK and PD models to predict the impact of genotypic variability, formulation differences, differences in target binding capacity and target site drug concentrations on drug responses and variability. Front Pharmacol. 2014;5:258. doi: 10.3389/fphar.2014.00258.

21. Cole SW, Capitanio JP, Chun K, Arevalo JMG, Ma J, Cacioppo JT. Myeloid differentiation architecture of leukocyte transcriptome dynamics in perceived social isolation. Proc Natl Acad Sci. 2015. doi:10.1073/pnas.1514249112.

22. Csajka C, Verotta D. Pharmacokinetic-pharmacodynamic modelling: history and perspectives. J Pharmacokinet Pharmacodyn. 2006;33(3):227-79. doi:10.1007/s10928-0059002-0.

23. Csete ME, Doyle JC. Reverse engineering of biological complexity. Science. 2002;295(5560):1664-9. doi:10.1126/science. 1069981.

24. de la Fuente-Fernandez R, Ruth TJ, Sossi V, Schulzer M, Calne DB, Stoessl AJ. Expectation and dopamine release: mechanism of the placebo effect in Parkinson's disease. Science. 2001;293(5532):1164-6. doi:10.1126/science.1060937.

25. Dickschen K, Eissing T, Murdter T, Schwab M, Willmann S, Hempel G. Concomitant use of tamoxifen and endoxifen in postmenopausal early breast cancer: prediction of plasma levels by physiologically-based pharmacokinetic modeling. Springer Plus. 2014;3:285. doi:10.1186/2193-1801-3-285.

26. Dopico XC, Evangelou M, Ferreira RC, Guo H, Pekalski ML, Smyth DJ, et al. Widespread seasonal gene expression reveals annual differences in human immunity and physiology. Nat Commun. 2015;6:7000. doi:10.1038/ncomms8000.

27. Drager A, Palsson BO. Improving collaboration by standardization efforts in systems biology. Front Bioeng Biotechnol. 2014;2: 61. doi:10.3389/fbioe.2014.00061.

28. Egger G. In search of a germ theory equivalent for chronic disease. Prev Chronic Dis. 2012;9, E95.

29. Egger G, Dixon J. Beyond obesity and lifestyle: a review of 21st century chronic disease determinants. Biomed Res Int. 2014;2014: 731685. doi: $10.1155 / 2014 / 731685$.

30. Einolf HJ. Comparison of different approaches to predict metabolic drug-drug interactions. Xenobiotica. 2007;37(10-11):1257-94. doi:10.1080/00498250701620700.

31. Ermakov S, Forster P, Pagidala J, Miladinov M, Wang A, Baillie R, et al. Virtual Systems Pharmacology (ViSP) software for simulation from mechanistic systems-level models. Front Pharmacol. 2014;5:232. doi:10.3389/fphar.2014.00232.

32. Friedrich CM. A model qualification method for mechanistic physiological QSP models to support model-informed drug development. CPT Pharmacometrics Syst Pharmacol. 2016;5(2):4353. doi:10.1002/psp4.12056.

33. Fung HL, Jusko WJ. Perspectives on the history and scientific contributions of Gerhard Levy. J Pharmacokinet Pharmacodyn. 2015;42(5):429-46. doi:10.1007/s10928-015-9442-0.

34. Gaines LD, Gaddy JL. Process optimization by flow sheet simulation. Ind Eng Chem Process Des Dev. 1976;15(1):206-11. doi: 10.1021/i260057a035. 
35. Gao ZG, Ye JP. Why do anti-inflammatory therapies fail to improve insulin sensitivity? Acta Pharmacol Sin. 2012;33(2):182-8. doi:10.1038/aps.2011.131.

36. Geoffroy PA, Fovet T, Micoulaud-Franchi JA, Boudebesse C, Thomas P, Etain B, et al. Bright light therapy in seasonal bipolar depressions. Encéphale. 2015;41(6):527-33. doi:10.1016/j.encep. 2015.09.003.

37. Ghosh S, Matsuoka Y, Asai Y, Hsin KY, Kitano H. Toward an integrated software platform for systems pharmacology. Biopharm Drug Dispos. 2013;34(9):508-26. doi:10.1002/bdd.1875.

38. Hall KT, Loscalzo J, Kaptchuk TJ. Genetics and the placebo effect: the placebome. Trends Mol Med. 2015;21(5):285-94. doi:10. 1016/j.molmed.2015.02.009.

39. Hamberg AK, Hellman J, Dahlberg J, Jonsson EN, Wadelius M. A Bayesian decision support tool for efficient dose individualization of warfarin in adults and children. BMC Med Inf Decis Making. 2015;15:7. doi:10.1186/s12911-014-0128-0.

40. Hamburg MA, Collins FS. The path to personalized medicine. N Engl J Med. 2010;363(4):301-4. doi:10.1056/NEJMp1006304.

41. Hatori M, Vollmers C, Zarrinpar A, DiTacchio L, Bushong EA, Gill S, et al. Time-restricted feeding without reducing caloric intake prevents metabolic diseases in mice fed a high-fat diet. Cell Metab. 2012;15(6):848-60. doi:10.1016/j.cmet.2012.04.019.

42. Hazra A, Krzyzanski W, Jusko WJ. Mathematical assessment of properties of precursor-dependent indirect pharmacodynamic response models. J Pharmacokinet Pharmacodyn. 2006;33(6):683717. doi:10.1007/s10928-006-9030-4.

43. Hogeweg P. The roots of bioinformatics in theoretical biology. PLoS Comput Biol. 2011;7(3), e1002021. doi:10.1371/journal. pcbi.1002021.

44. Hucka M, Finney A, Sauro HM, Bolouri H, Doyle JC, Kitano H, et al. The systems biology markup language (SBML): a medium for representation and exchange of biochemical network models. Bioinformatics. 2003;19(4):524-31.

45. Hucka M, Finney A, Bornstein BJ, Keating SM, Shapiro BE, Matthews J, et al. Evolving a lingua franca and associated software infrastructure for computational systems biology: the Systems Biology Markup Language (SBML) project. Syst Biol (Stevenage). 2004;1(1):41-53.

46. Iikuni N, Nakajima A, Inoue E, Tanaka E, Okamoto H, Hara M, et al. What's in season for rheumatoid arthritis patients? Seasonal fluctuations in disease activity. Rheumatology (Oxford). 2007;46(5):846-8. doi:10.1093/rheumatology/kel414.

47. Jin JY, Almon RR, DuBois DC, Jusko WJ. Modeling of corticosteroid pharmacogenomics in rat liver using gene microarrays. J Pharmacol Exp Ther. 2003;307(1):93-109. doi:10.1124/jpet.103. 053256 .

48. Joyner MJ, Pedersen BK. Ten questions about systems biology. J Physiol. 2011;589(Pt 5):1017-30. doi:10.1113/jphysiol.2010. 201509.

49. Jusko WJ. Moving from basic toward systems pharmacodynamic models. J Pharm Sci. 2013;102(9):2930-40. doi:10.1002/jps. 23590.

50. Kambayashi A, Blume H, Dressman J. Understanding the in vivo performance of enteric coated tablets using an in vitro-in silico-in vivo approach: case example diclofenac. Eur J Pharm Biopharm. 2013;85(3 Pt B):1337-47. doi:10.1016/j.ejpb.2013. 09.009.

51. Kamisoglu K, Sukumaran S, Nouri-Nigjeh E, Tu C, Li J, Shen X, et al. Tandem analysis of transcriptome and proteome changes after a single dose of corticosteroid: a systems approach to liver function in pharmacogenomics. OMICS. 2015;19(2):80-91. doi: 10.1089/omi.2014.0130.

52. Karatsoreos IN, McEwen BS. Psychobiological allostasis: resistance, resilience and vulnerability. Trends Cogn Sci. 2011;15(12): 576-84. doi:10.1016/j.tics.2011.10.005.
53. Kidd BA, Wroblewska A, Boland MR, Agudo J, Merad M, Tatonetti NP, et al. Mapping the effects of drugs on the immune system. Nat Biotechnol. 2015. doi:10.1038/nbt.3367.

54. Kimko HC, Duffull SB. Simulation for designing clinical trials: a pharmacokinetic-pharmacodynamic modeling perspective. Drugs and the pharmaceutical sciences, vol. 127. New York: Marcel Dekker; 2003.

55. Kimko HC, Peck CC, American Association of Pharmaceutical Scientists. Clinical trial simulations: applications and trends, AAPS advances in the pharmaceutical sciences series, vol. 1. New York: AAPS Press, Springer; 2011.

56. Klipp E, Liebermeister W, Helbig A, Kowald A, Schaber J. Systems biology standards-the community speaks. Nat Biotechnol. 2007;25(4):390-1. doi:10.1038/nbt0407-390.

57. Koch G, Schropp J. Solution and implementation of distributed lifespan models. J Pharmacokinet Pharmacodyn. 2013;40(6):639_ 50. doi:10.1007/s10928-013-9336-y.

58. Kohl M. Standards, databases, and modeling tools in systems biology. Methods Mol Biol. 2011;696:413-27. doi:10.1007/9781-60761-987-1 26.

59. Kostewicz ES, Aarons L, Bergstrand M, Bolger MB, Galetin A, Hatley $\mathrm{O}$, et al. PBPK models for the prediction of in vivo performance of oral dosage forms. Eur J Pharm Sci. 2014;57:300-21. doi:10.1016/j.ejps.2013.09.008

60. Krstic D, Knuesel I. Deciphering the mechanism underlying lateonset Alzheimer disease. Nat Rev Neurol. 2013;9(1):25-34. doi: 10.1038/nrneurol.2012.236.

61. Krstic D, Madhusudan A, Doehner J, Vogel P, Notter T, Imhof C, et al. Systemic immune challenges trigger and drive Alzheimerlike neuropathology in mice. J Neuroinflammation. 2012;9:151. doi:10.1186/1742-2094-9-151.

62. Krzyzanski W, Jusko WJ. Mathematical formalism and characteristics of four basic models of indirect pharmacodynamic responses for drug infusions. J Pharmacokinet Biopharm. 1998;26(4):385-408.

63. Kumar V, Rani S, Malik S, Trivedi AK, Schwabl I, Helm B, et al. Daytime light intensity affects seasonal timing via changes in the nocturnal melatonin levels. Naturwissenschaften. 2007;94(8): 693-6. doi:10.1007/s00114-007-0243-1.

64. Kyrmizi I, Hatzis P, Katrakili N, Tronche F, Gonzalez FJ, Talianidis I. Plasticity and expanding complexity of the hepatic transcription factor network during liver development. Genes Dev. 2006;20(16):2293-305. doi:10.1101/gad.390906.

65. Laroux FS. Mechanisms of inflammation: the good, the bad and the ugly. Front Biosci. 2004;9:3156-62.

66. Lehrer P, Karavidas MK, Lu SE, Coyle SM, Oikawa LO, Macor $\mathrm{M}$, et al. Voluntarily produced increases in heart rate variability modulate autonomic effects of endotoxin induced systemic inflammation: an exploratory study. Appl Psychophysiol Biofeedback. 2010;35(4):303-15. doi:10.1007/s10484-0109139-5.

67. Leil TA, Bertz R. Quantitative Systems Pharmacology can reduce attrition and improve productivity in pharmaceutical research and development. Front Pharmacol. 2014;5:247. doi:10.3389/fphar. 2014.00247.

68. Levy G. Relationship between elimination rate of drugs and rate of decline of their pharmacologic effects. J Pharm Sci. 1964;53: 342-3.

69. Levy G. Kinetics of pharmacologic effects. Clin Pharmacol Ther. 1966;7(3):362-72.

70. Li XM, Delaunay F, Dulong S, Claustrat B, Zampera S, Fujii Y, et al. Cancer inhibition through circadian reprogramming of tumor transcriptome with meal timing. Cancer Res. 2010;70(8):335160. doi:10.1158/0008-5472.CAN-09-4235.

71. Libby P. Inflammatory mechanisms: the molecular basis of inflammation and disease. Nutr Rev. 2007;65(12 Pt 2):S140-6. 
72. Liepe J, Kirk P, Filippi S, Toni T, Barnes CP, Stumpf MP. A framework for parameter estimation and model selection from experimental data in systems biology using approximate Bayesian computation. Nat Protoc. 2014;9(2):439-56. doi: 10.1038/nprot.2014.025.

73. Lunn D, Best N, Spiegelhalter D, Graham G, Neuenschwander B. Combining MCMC with 'sequential' PKPD modelling. J Pharmacokinet Pharmacodyn. 2009;36(1):19-38. doi:10.1007/ s10928-008-9109-1.

74. Mager DE, Jusko WJ. Development of translational pharmacokinetic-pharmacodynamic models. Clin Pharmacol Ther. 2008;83(6):909-12. doi:10.1038/clpt.2008.52.

75. Maharaj AR, Edginton AN. Physiologically based pharmacokinetic modeling and simulation in pediatric drug development. CPT Pharmacometrics Syst Pharmacol. 2014;3, e150. doi:10. 1038/psp.2014.45.

76. Mathias NR, Crison J. The use of modeling tools to drive efficient oral product design. AAPS J. 2012;14(3):591-600. doi:10.1208/ s12248-012-9372-3.

77. Maywood ES, Fraenkel E, McAllister CJ, Wood N, Reddy AB, Hastings $\mathrm{MH}$, et al. Disruption of peripheral circadian timekeeping in a mouse model of Huntington's disease and its restoration by temporally scheduled feeding. J Neurosci. 2010;30(30):10199204. doi:10.1523/JNEUROSCI.1694-10.2010.

78. McEwen BS. Allostasis and allostatic load: implications for neuropsychopharmacology. Neuropsychopharmacol: Off Publ Am Coll Neuropsychopharmacol. 2000;22(2):108-24. doi:10. 1016/S0893-133X(99)00129-3.

79. Meyer W. Is cancer a systemic disease? Ann Surg. 1931;93(1): 35-9.

80. Morris JK, Honea RA, Vidoni ED, Swerdlow RH, Burns JM. Is Alzheimer's disease a systemic disease? Biochim Biophys Acta (BBA) - Mol Basis Dis. 2014;1842(9):1340-9. doi:10.1016/j. bbadis.2014.04.012.

81. Nguyen TT, Almon RR, Dubois DC, Jusko WJ, Androulakis IP. Comparative analysis of acute and chronic corticosteroid pharmacogenomic effects in rat liver: transcriptional dynamics and regulatory structures. BMC Bioinf. 2010;11:515. doi:10. 1186/1471-2105-11-515.

82. Nguyen TT, Foteinou PT, Calvano SE, Lowry SF, Androulakis IP. Computational identification of transcriptional regulators in human endotoxemia. PLoS One. 2011;6(5), e18889. doi:10.1371/ journal.pone.0018889.

83. Nguyen TT, Almon RR, Dubois DC, Sukumaran S, Jusko WJ, Androulakis IP. Tissue-specific gene expression and regulation in liver and muscle following chronic corticosteroid administration. Gene Regul Syst Biol. 2014;8:75-87. doi:10.4137/GRSB. S13134.

84. Pattison RC, Baldea M. Equation-oriented flowsheet simulation and optimization using pseudo-transient models. AIChE J. 2014;60(12):4104-23. doi:10.1002/aic.14567.

85. Peterson MC, Riggs MM. FDA Advisory Meeting Clinical Pharmacology review utilizes a Quantitative Systems Pharmacology (QSP) model: a watershed moment? CPT Pharmacometrics Syst Pharmacol. 2015;4(3), e00020. doi:10. 1002/psp4.20.

86. Quan N, Banks WA. Brain-immune communication pathways. Brain Behav Immun. 2007;21(6):727-35. doi:10.1016/j.bbi. 2007.05.005.

87. Quera Salva MA, Hartley S, Barbot F, Alvarez JC, Lofaso F, Guilleminault C. Circadian rhythms, melatonin and depression. Curr Pharm Des. 2011;17(15):1459-70.

88. Redig AJ, McAllister SS. Breast cancer as a systemic disease: a view of metastasis. J Intern Med. 2013;274(2):113-26. doi:10. 1111/joim. 12084
89. Rein MJ, Renouf M, Cruz-Hernandez C, Actis-Goretta L, Thakkar SK, da Silva Pinto M. Bioavailability of bioactive food compounds: a challenging journey to bioefficacy. Br J Clin Pharmacol. 2013;75(3):588-602. doi:10.1111/j.1365-2125.2012. 04425.x.

90. Rullmann JA, Struemper H, Defranoux NA, Ramanujan S, Meeuwisse CM, van Elsas A. Systems biology for battling rheumatoid arthritis: application of the Entelos PhysioLab platform. Syst Biol (Stevenage). 2005;152(4):256-62.

91. Sager JE, Yu J, Ragueneau-Majlessi I, Isoherranen N. Physiologically Based Pharmacokinetic (PBPK) modeling and simulation approaches: a systematic review of published models, applications, and model verification. Drug Metab Dispos. 2015;43(11):1823-37. doi:10.1124/dmd.115.065920.

92. Sauro HM, Hucka M, Finney A, Wellock C, Bolouri H, Doyle J, et al. Next generation simulation tools: the Systems Biology Workbench and BioSPICE integration. OMICS. 2003;7(4):35572. doi:10.1089/153623103322637670.

93. Schaller S, Willmann S, Lippert J, Schaupp L, Pieber TR, Schuppert A, et al. A generic integrated physiologically based whole-body model of the glucose-insulin-glucagon regulatory system. CPT Pharmacometrics Syst Pharmacol. 2013;2(8):1-10. doi:10.1038/psp.2013.40.

94. Schibler U, Ripperger J, Brown SA. Peripheral circadian oscillators in mammals: time and food. J Biol Rhythm. 2003;18(3):250 60. doi:10.1177/0748730403018003007.

95. Schmidt BJ, Casey FP, Paterson T, Chan JR. Alternate virtual populations elucidate the type I interferon signature predictive of the response to rituximab in rheumatoid arthritis. BMC Bioinf. 2013;14:221. doi:10.1186/1471-2105-14-221.

96. Shapiro BE, Hucka M, Finney A, Doyle J. MathSBML: a package for manipulating SBML-based biological models. Bioinformatics. 2004;20(16):2829-31. doi:10.1093/bioinformatics/bth271.

97. Shoda L, Kreuwel H, Gadkar K, Zheng Y, Whiting C, Atkinson $\mathrm{M}$, et al. The type 1 diabetes PhysioLab Platform: a validated physiologically based mathematical model of pathogenesis in the non-obese diabetic mouse. Clin Exp Immunol. 2010;161(2):250 67. doi:10.1111/j.1365-2249.2010.04166.x.

98. Shono Y, Jantratid E, Kesisoglou F, Reppas C, Dressman JB. Forecasting in vivo oral absorption and food effect of micronized and nanosized aprepitant formulations in humans. Eur J Pharm Biopharm. 2010;76(1):95-104. doi:10.1016/j.ejpb.2010.05.009.

99. Smith DA. Evolution of ADME science: where else can modeling and simulation contribute? Mol Pharm. 2013;10(4):1162-70. doi: 10.1021/mp3005319.

100. Smolensky MH, Portaluppi F, Manfredini R, Hermida RC, Tiseo R, Sackett-Lundeen LL, et al. Diurnal and twenty-four hour patterning of human diseases: acute and chronic common and uncommon medical conditions. Sleep Med Rev. 2015;21:12-22. doi:10. 1016/j.smrv.2014.06.005.

101. Sorger PK, Allerheiligen SR, Abernethy DR, Altman RB, Brouwer KL, Califano A et al. editors. Quantitative and systems pharmacology in the post-genomic era: new approaches to discovering drugs and understanding therapeutic mechanisms. An NIH white paper by the QSP workshop group; 2011: NIH Bethesda.

102. Spies CM, Straub RH, Buttgereit F. Energy metabolism and rheumatic diseases: from cell to organism. Arthritis Res Ther. 2012;14(3):216. doi:10.1186/ar3885.

103. Sterling P. Allostasis: a model of predictive regulation. Physiol Behav. 2012;106(1):5-15. doi:10.1016/j.physbeh.2011.06.004.

104. Sterling P. Principle of allostasis: optimal design, predictive regulation, pathophysiology and rational therapeutics. In: Schulkin J, editor. Allostasis, homeostasis and the cost of adaptation. MIT Press; 2003. 
105. Straub RH. Concepts of evolutionary medicine and energy regulation contribute to the etiology of systemic chronic inflammatory diseases. Brain Behav Immun. 2011;25(1):1-5. doi:10.1016/j.bbi. 2010.08.002.

106. Straub RH. Evolutionary medicine and chronic inflammatory state-known and new concepts in pathophysiology. J Mol Med (Berl). 2012;90(5):523-34. doi:10.1007/s00109-012-0861-8.

107. Straub RH, Besedovsky HO. Integrated evolutionary, immunological, and neuroendocrine framework for the pathogenesis of chronic disabling inflammatory diseases. FASEB J. 2003;17(15):217683. doi:10.1096/fj.03-0433hyp.

108. Straub RH, Cutolo M, Buttgereit F, Pongratz G. Energy regulation and neuroendocrine-immune control in chronic inflammatory diseases. J Intern Med. 2010;267(6):543-60. doi:10.1111/j.13652796.2010.02218.x.

109. Streeter CC, Gerbarg PL, Saper RB, Ciraulo DA, Brown RP. Effects of yoga on the autonomic nervous system, gammaaminobutyric-acid, and allostasis in epilepsy, depression, and post-traumatic stress disorder. Med Hypotheses. 2012;78(5): 571-9. doi:10.1016/j.mehy.2012.01.021.

110. Sunderram J, Sofou S, Kamisoglu K, Karantza V, Androulakis IP. Time-restricted feeding and the realignment of biological rhythms: translational opportunities and challenges. J Transl Med. 2014;12: 79. doi:10.1186/1479-5876-12-79.

111. Tabas I, Glass CK. Anti-inflammatory therapy in chronic disease: challenges and opportunities. Science. 2013;339(6116):166-72. doi:10.1126/science. 1230720 .

112. van der Graaf PH, Benson N. Systems pharmacology: bridging systems biology and pharmacokinetics-pharmacodynamics (PKPD) in drug discovery and development. Pharm Res. 2011;28(7):1460-4. doi:10.1007/s11095-011-0467-9.

113. Verotta D. Fractional dynamics pharmacokineticspharmacodynamic models. J Pharmacokinet Pharmacodyn. 2010;37(3):257-76. doi:10.1007/s10928-010-9159-z.

114. Visweswaraiah NK, Telles S. Randomized trial of yoga as a complementary therapy for pulmonary tuberculosis. Respirology. 2004;9(1):96-101. doi:10.1111/j.1440-1843.2003.00528.x.
115. Vitalo A, Fricchione J, Casali M, Berdichevsky Y, Hoge EA, Rauch SL, et al. Nest making and oxytocin comparably promote wound healing in isolation reared rats. PLoS One. 2009;4(5), e5523. doi:10.1371/journal.pone.0005523.

116. von Kanel R. Fear of terror and inflammation ignite heart health decline. Proc Natl Acad Sci U S A. 2015;112(5):1248-9. doi:10. 1073/pnas.1424405112.

117. Williams R, Timmis J, Qwarnstrom E. Computational models of the NF-KB signalling pathway. Computation. 2014;2(4):131.

118. Wist AD, Berger SI, Iyengar R. Systems pharmacology and genome medicine: a future perspective. Genome Med. 2009;1(1):11. doi:10.1186/gm11.

119. Wright DF, Duffull SB. Development of a bayesian forecasting method for warfarin dose individualization. Pharm Res. 2011;28(5):1100-11. doi:10.1007/s11095-011-0369-x.

120. Wright DF, Winter HR, Duffull SB. Understanding the time course of pharmacological effect: a PKPD approach. Br J Clin Pharmacol. 2011;71(6):815-23. doi:10.1111/j.1365-2125.2011. 03925.x.

121. Yao Z, Krzyzanski W, Jusko WJ. Assessment of basic indirect pharmacodynamic response models with physiological limits. J Pharmacokinet Pharmacodyn. 2006;33(2):167-93. doi:10.1007/ s10928-006-9003-7.

122. Yao Z, Hoffman EP, Ghimbovschi S, Dubois DC, Almon RR, Jusko WJ. Mathematical modeling of corticosteroid pharmacogenomics in rat muscle following acute and chronic methylprednisolone dosing. Mol Pharm. 2008;5(2):328-39. doi: $10.1021 / \mathrm{mp} 700094 \mathrm{~s}$.

123. Ye J, Keller JN. Regulation of energy metabolism by inflammation: a feedback response in obesity and calorie restriction. Aging (Albany NY). 2010;2(6):361-8.

124. Yoon JA, Han DH, Noh JY, Kim MH, Son GH, Kim K, et al. Meal time shift disturbs circadian rhythmicity along with metabolic and behavioral alterations in mice. PLoS One. 2012;7(8), e44053. doi: 10.1371/journal.pone.0044053. 